УДК 378

$10.17213 / 2075-2067-2021-1-140-149$

\title{
ПЕРСПЕКТИВЫ ИСПОЛЬЗОВАНИЯ ЦИФРОВЫХ ТЕХНОЛОГИЙ НА ПРОМЫШЛЕННЫХ ПРЕДПРИЯТИЯХ РОСТОВСКОЙ ОБЛАСТИ
}

\author{
(C) 2021 г. А. М. Калинина, М. М. Куликов
}

\section{Южно-Российский государственный политехнический университет (НПИ) имени М. И. Платова, г. Новочеркасск, Россия}

Целью исследования является выявление специфики применения циифровых технологий на промышленных предприятиях Ростовской области, обусловленное располагаемыми ресурсами спецификой деятельности предприятий.

Методологическую базу исследования представляют нормативно-правовые акты по иифрровизации, статистические данные российских рейтингов промышленного развития, научные публикации, аналитические и отраслевые отчеты по иүифровизаџии, а также структурный анализ и элементы сравнительного анализа. Применение этих методов и подходов позволяет изучить используемые в промышленности циифровые технологии, их достоинства и недостатки, спрогнозировать предполагаемые результаты от их внедрения.

Результаты исследования. Одним из важных результатов является алгоритм внедрения циифровых технологий на промышленном предприятии, разработанный на основе выявленных закономерностей текущеего распространения циифровизащии на крупных предприятиях Ростовской области. Полагаем, что существенное влияние на внедрение IT-технологий оказывает специфика деятельности предприятия, а также имеюшиеся отечественные циирровые технологии. Однако при использовании циирровых технологий стоит предусмотреть увеличение рисков для предприятия и значительные затраты на подготовку инфраструктуры, оборудования и переподготовку кадрового состава.

Перспективу исследования составляет углубленньй анализ факторов, влияющих на распространение цицровизачии на промышленных предприятиях Ростовской области, а также исследование полезного эффекта от их внедрения.

Ключевые слова: иүифровизаџчия; наџчиональный проект; Ростовская область; IT-технологии; Индустрия 4.0.

\section{PROSPECTS FOR USE OF DIGITAL TECHNOLOGIES IN INDUSTRIAL ENTERPRISES OF THE ROSTOV REGION}

\author{
(C) 2021 A. M. Kalinina, M. M. Kulikov
}

\section{Platov South Russian State Polytechnic University (NPI), Novocherkassk, Russia}

The purpose of the study is to reveal the specifics of the use of digital technologies at industrial enterprises in Rostov region, due to available resources and the specifics of enterprises.

The methodological base of the study is represented by digitalization regulations, statistical data of Russian ratings of industrial development, scientific publications, analytical and industry reports on digitalization, as well as structural analysis and elements of comparative analysis. The application of these methods and approaches allows to study the applied in industry digital 
technologies, their advantages and disadvantages, and predict the expected results from its implementation.

The results of the study is an algorithm for the implementation of digital technologies in an industrial enterprise, developed on the basis of the revealed patterns of the current spread of digitalization at large enterprises in the Rostov region. We suppose that the specifics of the enterprise, as well as the existing national digital technologies, have a significant impact on the implementation of IT. technologies However, when using digital technologies, it is necessary to provide for increasing risks for the enterprise and significant costs for the preparation of infrastructure, equipment and training of personnel.

The prospect of the study is an in-depth analysis of the factors affecting the spread of digitalization in industrial enterprises of the Rostov region, as well as a study of the beneficial effect of its implementation.

Key words: digitalization; national project; Rostov region; IT-technologies; Industry 4.0.

Введение. Развитие и использование цифровых технологий на базе промышленных предприятий связано с развитием сети Интернет, благодаря которой можно оптимизировать многие технические процессы на предприятии.

Об активном использовании IT-технологий можно судить по результатам опроса, который проводился в начале 2020 г. Институтом статистических исследований и экономики знаний (ИСИЭЗ) НИУ ВШЭ. Так, более чем на $70 \%$ предприятий внедрены цифровые технологии. Стоит отметить, что наиболее распространенными IT-технологиями является использование промышленных роботов - 44,5\% организаций, применение технологии компьютерного инжиниринга $41,1 \%$ предприятий, а также цифровой сбор, обработка и анализ больших массивов данных — на 36\% предприятий [4].

Ростовская область является одним из крупнейших агропромышленных центров России с высоким уровнем развития промышленности и сельского хозяйства. Большую роль в развитии региона играют крупные промышленные предприятия, такие как ООО «Комбайновый завод «Ростсельмаш» в г. Ростове-на-Дону, ООО «ПК «НЭВЗ» в г. Новочеркасске, АО «Таганрогский металлургический завод» в г. Таганроге, ОАО «Миллеровосельмаш» в г. Миллерово и др. [10].

По мнению губернатора Ростовской области, необходимо активно включаться в процесс цифровизации для дальнейшего развития и региона в целом, и конкретных муниципалитетов. Он также отметил, что наглядным примером использования цифровых технологий является Новочеркасский электровозостроительный завод (НЭВ3) [3]. Так, в конце 2019 г. НЭВЗ во второй раз стал Лауреатом Первой промышленной премии OEE Award. Были высоко оценены результаты завода в цифровой сфере - представителям завода были вручены медаль и диплом за реализацию проекта сквозной цифровой трансформации основных бизнес-процессов предприятия.

Следует заметить, что проект «Цифровой завод НЭВЗ» является самым значительным проектом в сфере распространения цифровизации на промышленных предприятиях Ростовской области с использованием технологий «Индустрии 4.0» и представляет собой интегрированные производственные системы, которые реагируют в режиме реального времени на потребности заказчика в сети поставок.

Чтобы осознать масштаб внедрения цифровых технологий на промышленных предприятиях Ростовской области, можно проанализировать используемые цифровые технологии и предполагаемые результаты, которые будут достигнуты благодаря данным технологиям (табл. 1).

Необходимо отметить, что наряду с промышленностью сельское хозяйство является одной из ключевых отраслей экономики Ростовской области, составляя $14,2 \%$ в структуре ее валового регионального продукта. В настоящее время в регионе реализуется проект 


\begin{tabular}{|c|c|c|c|}
\hline \multirow{4}{*}{ 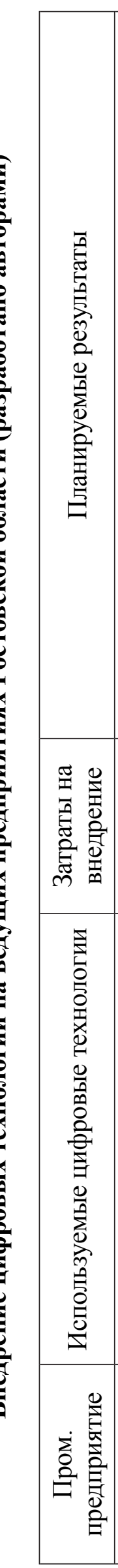 } & 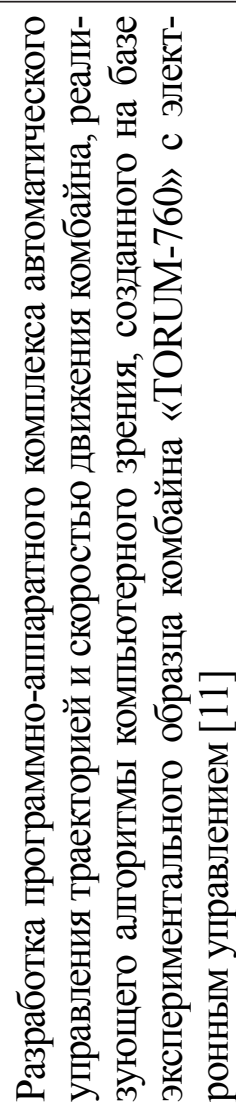 & 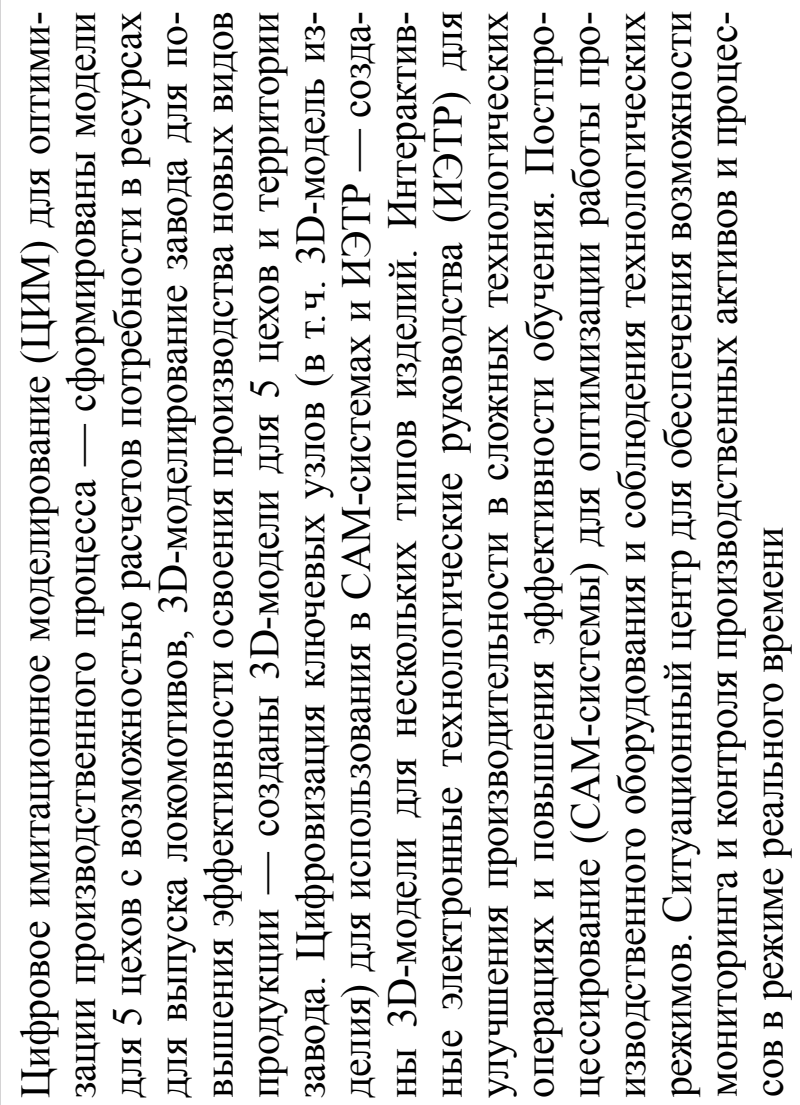 & 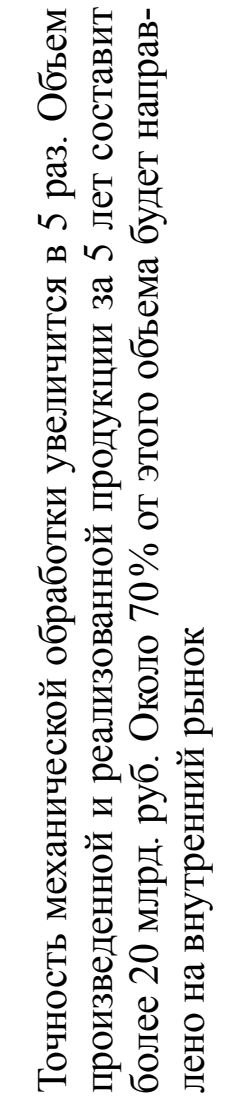 \\
\hline & 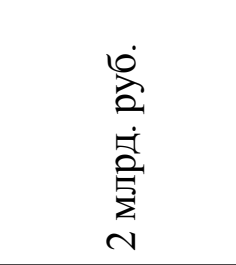 & 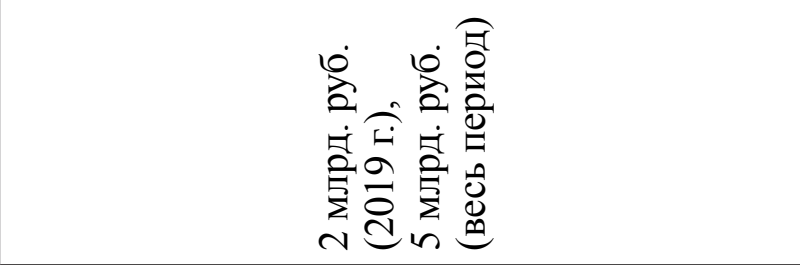 & 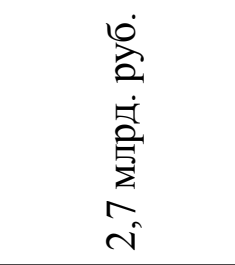 \\
\hline & 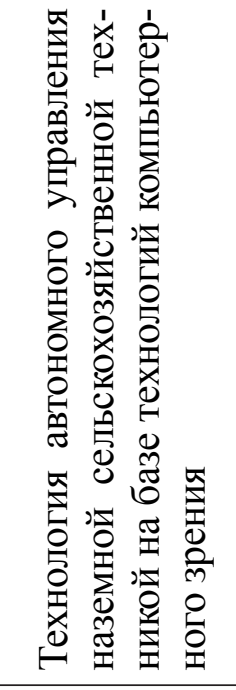 & 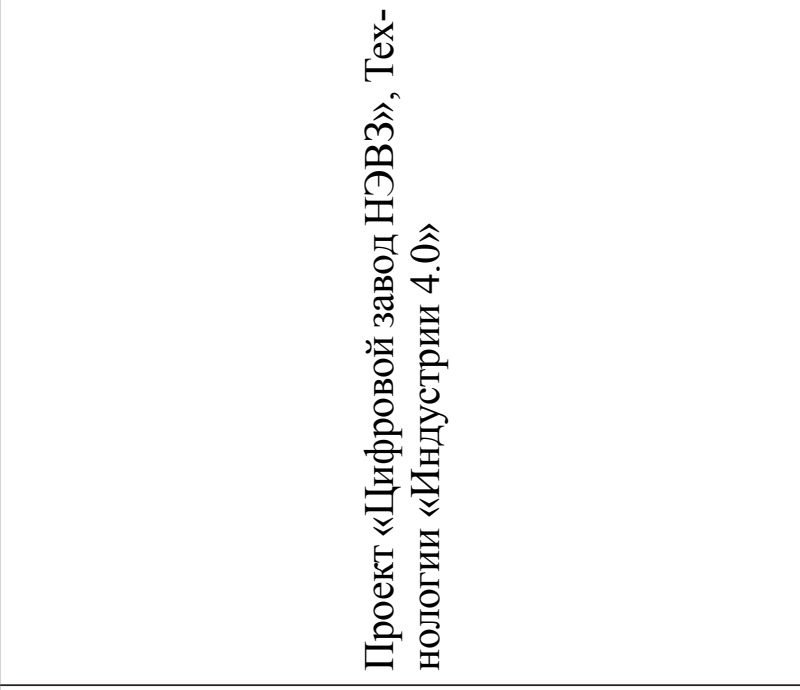 & 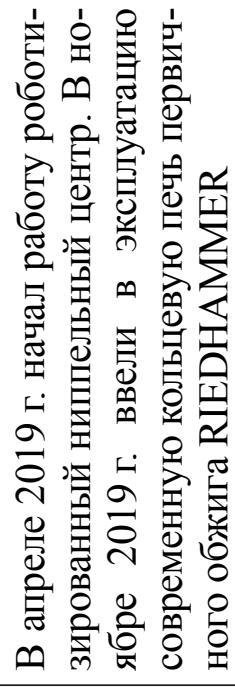 \\
\hline & 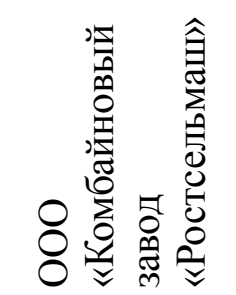 & ס光 & 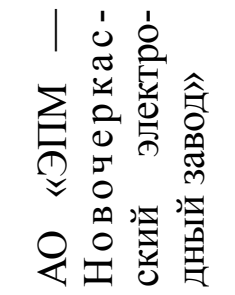 \\
\hline
\end{tabular}


ت્.

\begin{tabular}{|c|c|c|c|}
\hline 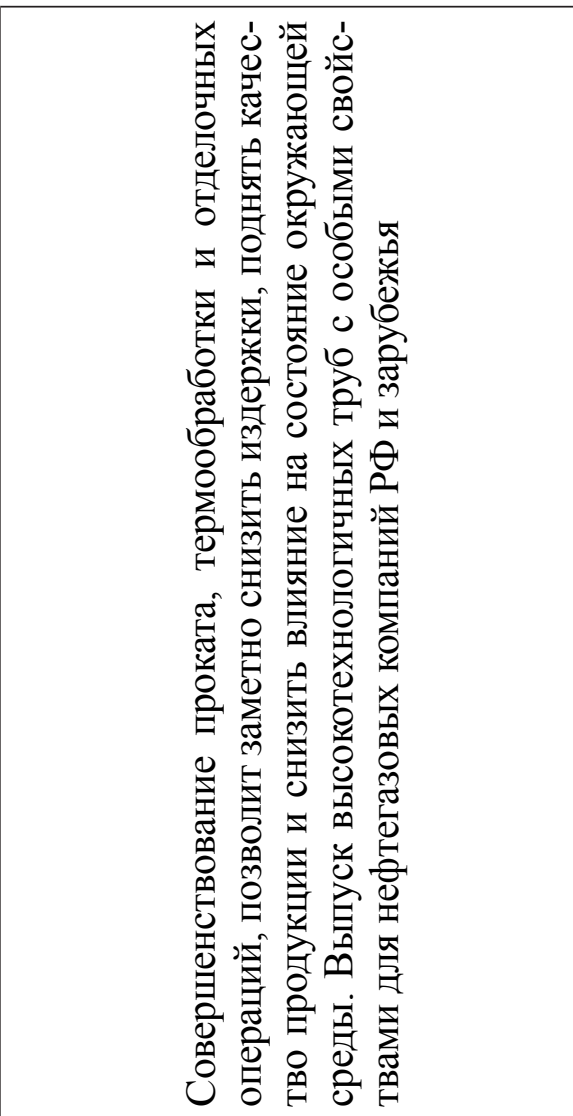 & 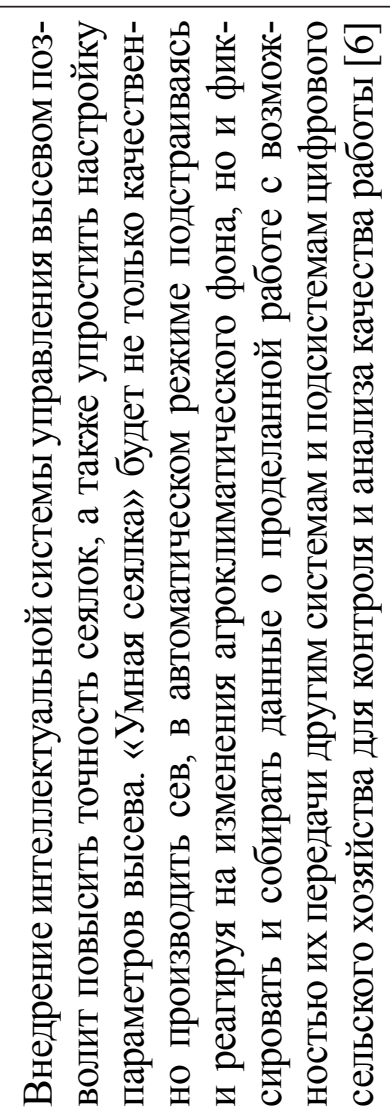 & 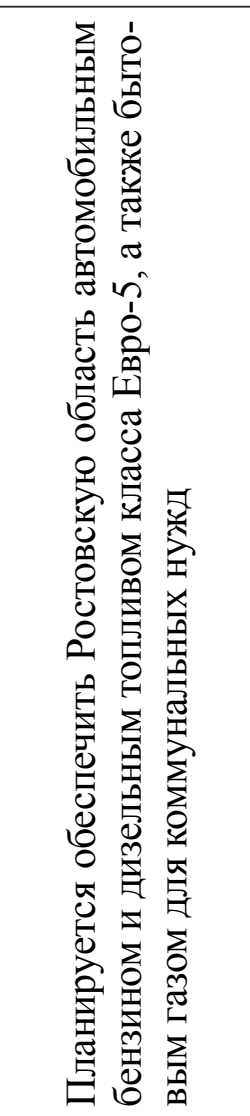 & 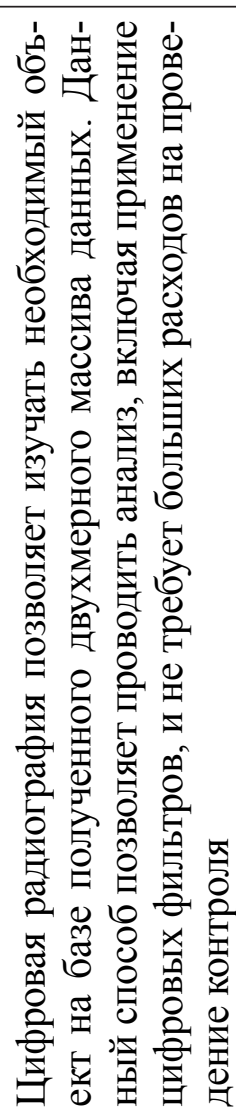 \\
\hline 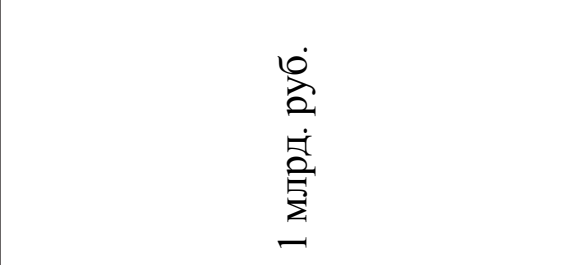 & 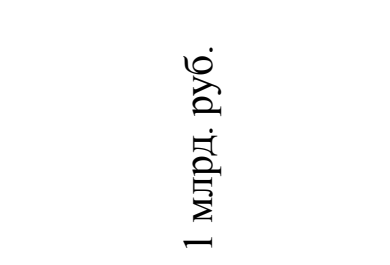 & 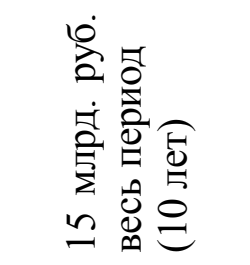 & 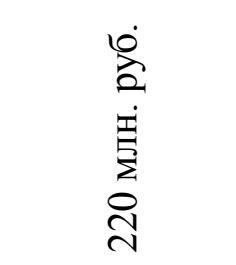 \\
\hline 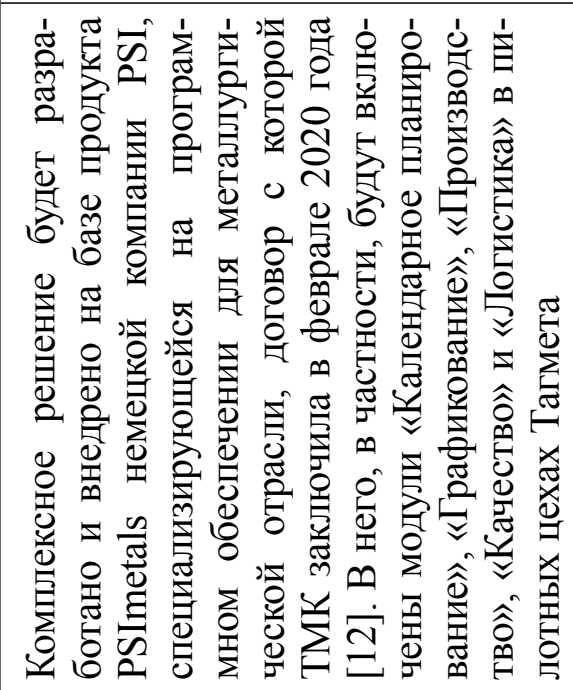 & 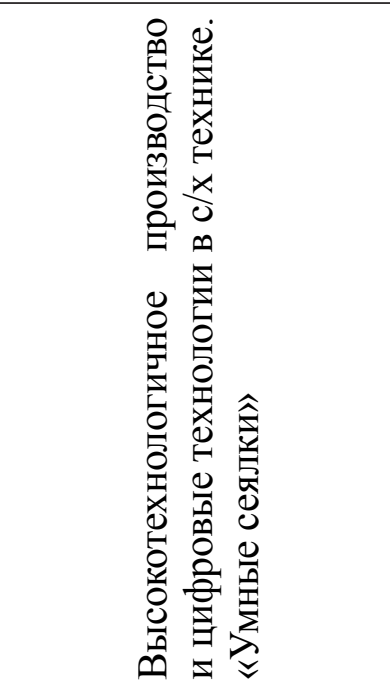 & 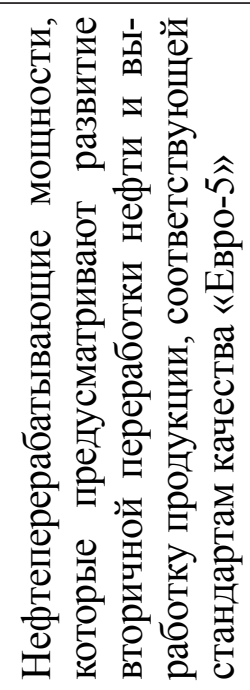 & 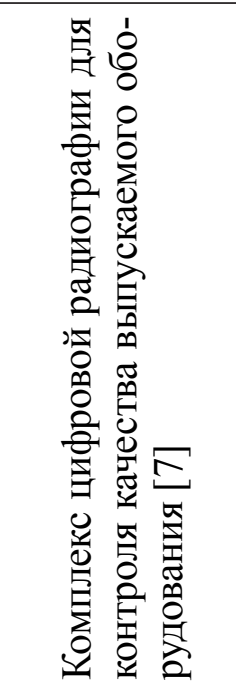 \\
\hline 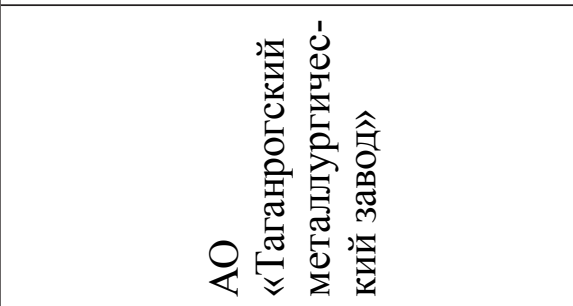 & 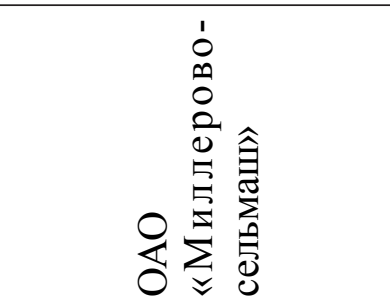 & 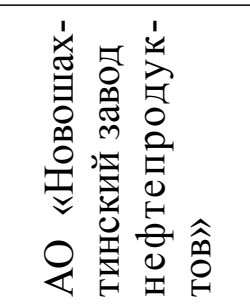 & 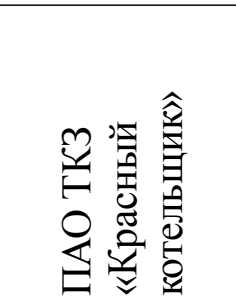 \\
\hline
\end{tabular}


«Цифровое сельское хозяйство», опыт реализации которого в части создания цифровой инфраструктуры и подготовки сотрудников будет полезен и для цифровизации промышленных предприятий.

Российский промышленный комплекс в целом делает только первые шаги к цифровой трансформации, считают эксперты [1]. В нашей стране еще нет сформированной цифровой экосистемы, которая отличает цифровизацию от простой автоматизации. Но цифровое развитие будет происходить вместе с консолидацией рынка. Пока у компаний не было жесткой необходимости в этом, но сейчас промышленность трансформируется, и внедрение цифровизации становится устойчивым конкурентным преимуществом предприятий.

Преимущества и недостатки применения IT-технологий. Разумеется, внедрение цифровых технологий на промышленном предприятии имеет как достоинства, так и недостатки (рис. 1). В частности, главным преимуществом использования цифровых технологий является упрощение многих процессов, вследствие чего происходит повышение производственных мощностей и повышается объем выпускаемой продукции [5]. Однако, внедрение IT-технологий требует больших затрат, наличие специальных навыков у кадров, а также несет больше рисков и, соответственно, больший ущерб при выходе из строя информационных систем.

К сожалению, в настоящее время есть ряд факторов, которые сдерживают развитие цифровизации в России [13]:

1) неготовность нормативно-правовой базы - данная проблема имеет комплексный характер, поскольку присуща всей российской промышленности, и ведет к большому отставанию от стран-лидеров цифровой промышленности (Великобритании, США, Китая, Германии, Франции);

2) отсутствие готовых отечественных решений и промышленных технологий, которые действительно можно внедрять на предприятиях на сегодняшний день.

Для решения данных проблем и устранения «цифрового» разрыва между Россией и ведущими странами проводится ряд мероприятий.
За последние несколько лет к ГерманоРоссийской инициативе по цифровизации экономики (GRID), основанной Восточным комитетом германской экономики и Российско-Германской внешнеторговой палатой (ВТП), присоединились компании Siemens, SAP, Bosch, РСПП, «Ростелеком», Фонд «Сколково» и «Цифра» (2017 г.), Volkswagen Group Rus, «РОСТЕХИНФОРМ», «ТМК» и Группа Синара (2019 г.) для реализации концепции «Индустрии 4.0» [2].

Можно заметить, что с реализацией приоритетных национальных проектов (в частности, нацпроекта «Цифровая экономика» 2019-2024 гг. [9], который предусматривает внедрение цифровых технологий во все сферы общественной жизни, а также соответствующее преобразование приоритетных отраслей экономики, включая промышленность) началось активное развитие цифровых технологий на российских предприятиях. В каждом субъекте РФ были разработаны соответствующие национальные программы, которые поэтапно регламентируют внедрение IT-технологий.

Так, в Ростовской области в рамках нацпроекта до 31 декабря 2024 г. действуют пять региональных проектов, предусматривающих качественные информационные изменения в управлении, подготовке кадров, развития инфраструктуры и обеспечения безопасности («Цифровые технологии» [8], «Цифровое государственное управление», «Кадры для цифровой экономики», «Информационная инфраструктура», «Информационная безопасность»).

Для успешного внедрения цифровых технологий на промышленном предприятии целесообразно использовать следующий алгоритм (рис. 2).

Заключение. Проанализировав использование информационных технологий в деятельности крупных промышленных предприятий Ростовской области, можно сделать вывод, что пока делаются только первые шаги по внедрению последних достижений цифровизации в регионе. Это связано с трудоемким процессом перехода на качественно новый информационный уровень, который требует больших материальных затрат, переподготовки кадров и изменений в инфраструктуре. 


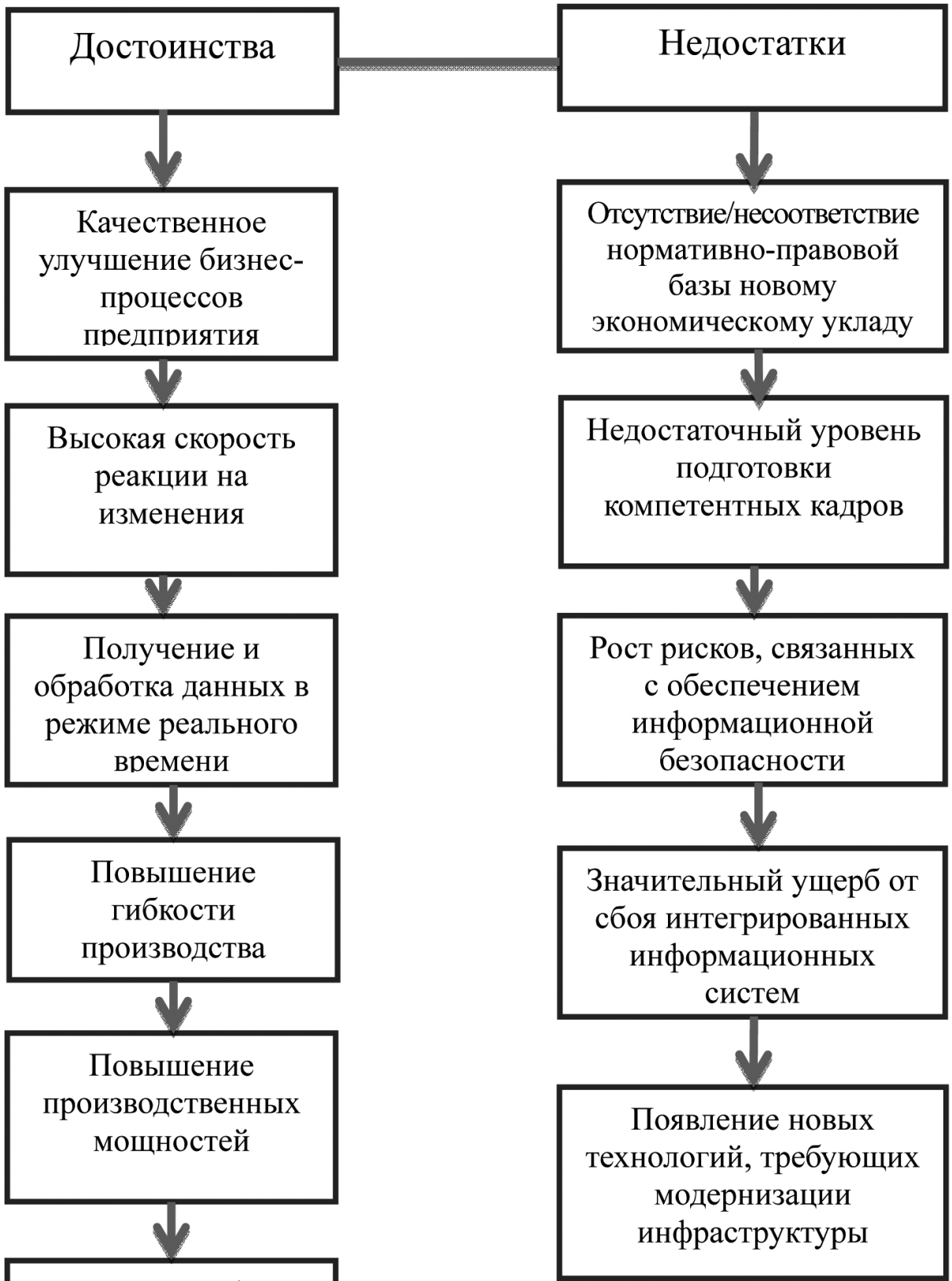

Увеличение объема выпускаемой продукции

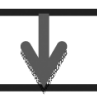

Интеграция этапов цикла выпускаемой продукции

Рис. 1. Достоинства и недостатки внедрения цифровых технологий на промышленном предприятии (разработано авторами) 


\section{Разработка стратегии перехода}

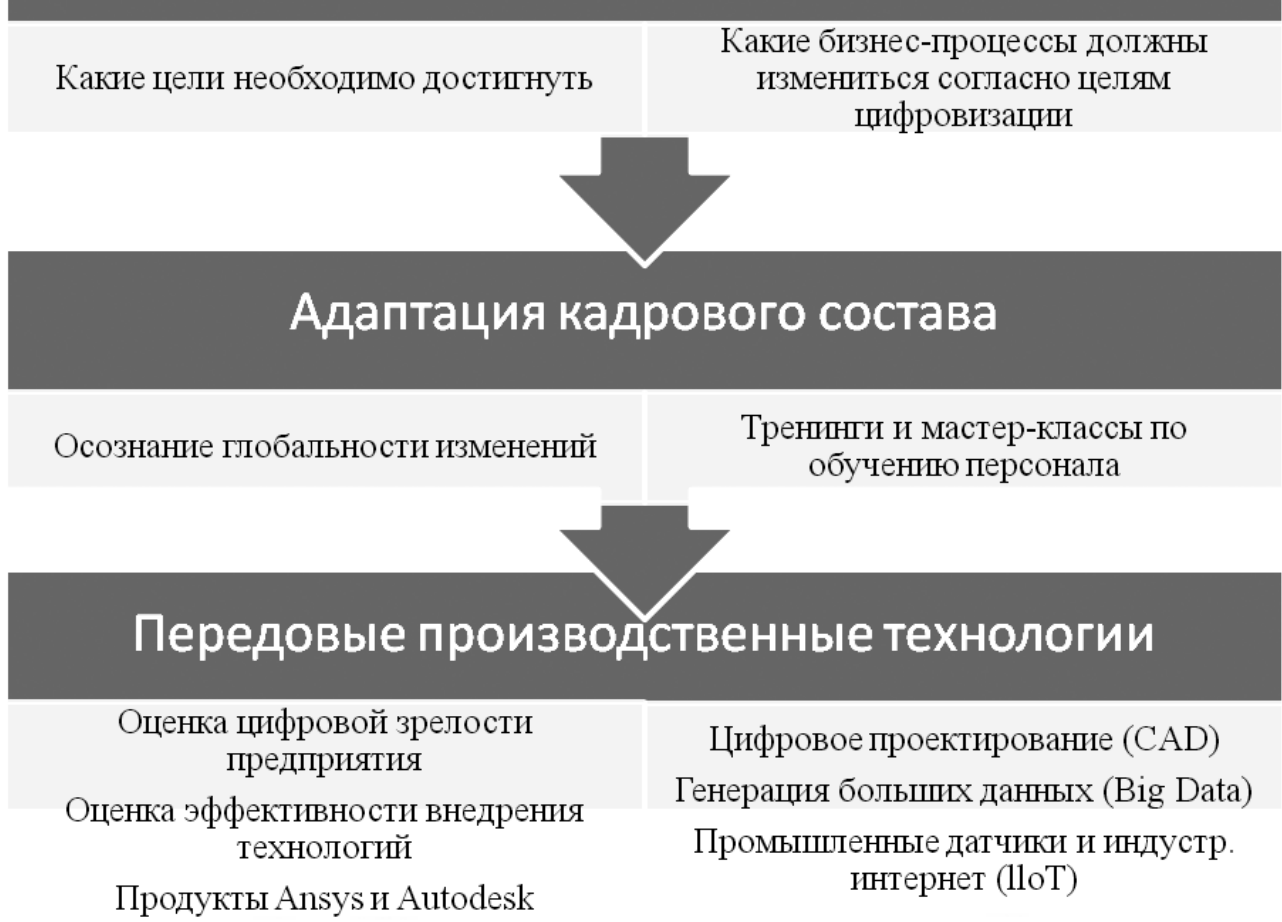

Рис. 2. Алгоритм внедрения цифровых технологий на промышленном предприятии (разработано авторами)

Существенными достижениями в информационной сфере пока отличаются только ООО «Комбайновый завод «Ростсельмаш», где разработана и успешно испытана технология автономного управления комбайнами, а также ООО «ПК «НЭВЗ», где разработана 3D-модель завода. Разумеется, предстоит еще много работы по внедрению цифровизации на промышленных предприятиях Ростовской области, однако в настоящее время имеются все предпосылки для перехода промышленности региона на новый цифровой уровень.

\section{Литература}

1. Авдеева И. Л. Цифровизация промышленных экономических систем: проблемы и последствия современных технологий // Известия Саратовского университета. 2019. - №3. - C. 238-245.

2. Баталова А. Страны-лидеры «Индустрии 4.0» // Российская газета. - 2019. №122.

3. Василий Голубев: «Цифровые технологии помогут Ростовской области стать лидером развития» от 28.07.2020 [Электронный ресурс]. - Режим доступа: https://www. donland.ru/news/10124/ (Дата обращения: 29.09.2020).

4. Коровин $Г$. Цифровизация промышленности в контексте новой индустриализации РФ // Общество и экономика. - 2018. №1. - С. 47-66.

5. Кунанбаева К. Б., Гончаренко Л. П. Цифровизация экономики - необходимое условие повышения эффективности промышленных производств // Самоуправление. 2019. - №2 (115). - С. 99-102.

6. «Миллеровосельмаш» в Ростовской области внедряет цифровые технологии в сельхозпроизводство от 22.12.2019 [Электронный ресурс]. - Режим доступа: https://nash-krai.ru/oblast/12648-umnyeseyalki-selkhozpredpriyatie-v-rostovskojoblasti-vnedryaet-tsifrovye-tekhnologii-vselkhozproizvodstvo (Дата обращения: 29.09.2020).

7. На ТКЗ «Красный котельщик» введен в эксплуатацию современный комплекс цифровой радиографии от 23.07.2020 [Элек- 
тронный ресурс]. - Режим доступа: https:// armtorg.ru/news/32397/ (Дата обращения: 29.09.2020).

8. Паспорт регионального проекта «Цифровые технологии (Ростовская область)» утвержден Советом по проектному управлению при Губернаторе Ростовской области (Протокол от 20.04.2020 г. №6).

9. Распоряжение Правительства РФ от 28.07.2017 г. №1632-р «Об утверждении программы “Цифровая экономика Российской Федерации"».

10. Рейтинг РБК Ростов: топ-10 промышленных компаний Дона за 2018 год от 21.08.2020 [Электронный ресурс]. — Режим доступа: https://rostov.rbc.ru/rostov/21/0 8/2019/5d5d26ef9a79471a78471a11/ (Дата обращения: 29.09.2020).

11. «Ростсельмаш» и ДГТУ займется цифровизацией агропромышленного комплекса от 14.07.2020 [Электронный peсурс]. — Режим доступа: https://rostselmash. com/company/press/news/show/1186/ (Дата обращения: 29.09.2020).

12. ТМК внедряет цифровые технологии в систему оперативного управления производством от 05.08.2020 [Электронный ресурс]. - Режим доступа: https://www.comnews.ru/digital-economy/ content/208464/2020-08-05/2020-w32/tmkvnedryaet-cifrovye-tekhnologii-sistemuoperativnogo-upravleniya-proizvodstvom (Дата обращения: 29.09.2020).

13. Федотова Г.В. Проблемы цифровизации промышленного сектора // Национальные интересы: приоритеты и безопасность. - 2019. — №2. - С. 273-283.

\section{References}

1. Avdeeva I.L. Cifrovizacija promyshlennyh jekonomicheskih sistem: problemy i posledstvija sovremennyh tehnologij [Digitalization of industrial economic systems: problems and consequences of modern technologies] // Izvestija Saratovskogo universiteta. - 2019. - №3. Pp. 238-245.

2. Batalova A. Strany-lidery «Industrii 4.0» [Countries-leaders of «Industry 4.0»] // Rossijskaja gazeta. - 2019. - №122.

3. Vasilij Golubev: «Cifrovye tehnologii pomogut Rostovskoj oblasti stat' liderom razvitija» ot 28.07.2020 [Vasily Golubev: «Digital technologies will help the Rostov region become a leader of development» from 28.07.2020] [Jelektronnyj resurs]. — URL: https://www.donland. ru/news/10124/ (Date accessed: 29.09.2020).

4. Korovin G. Cifrovizacija promyshlennosti v kontekste novoj industrializacii RF [Digitalization of industry in the context of the new industrialization of the Russian Federation] // Obshhestvo i jekonomika [Society and Economy]. - 2018. - №1. - Pp. 47-66.

5. Kunanbaeva K.B., Goncharenko L.P. Cifrovizacija jekonomiki - neobhodimoe uslovie povyshenija jeffektivnosti promyshlennyh proizvodstv [Digitalization of the economy - a necessary condition for improving the efficiency of industrial production] // Samoupravlenie. 2019. — №2 (115). — Pp. 99-102.

6. «Millerovosel'mash» v Rostovskoj oblasti vnedrjaet cifrovye tehnologii v sel'hozproizvodstvo ot 22.12.2019 [«Millerovoselmash» in the Rostov region introduces digital technologies in agricultural production from 22.12.2019] [Jelektronnyj resurs]. — URL: https://nash-krai.ru/oblast/12648umnye-seyalki-selkhozpredpriyatie-v-rostovskojoblasti-vnedryaet-tsifrovye-tekhnologii-v-selkhozproizvodstvo (Date accessed: 29.09.2020).

7. Na TKZ «Krasnyj kotel'shhik» vveden v jekspluataciju sovremennyj kompleks cifrovoj radiografii ot 23.07.2020 [A modern complex of digital radiography from 23.07.2020 was put into operation at the Krasny Kotelshchik Industrial Complex] [Jelektronnyj resurs]. — URL: https://armtorg.ru/news/32397/ (Date accessed: 29.09.2020).

8. Pasport regional'nogo proekta «Cifrovye tehnologii (Rostovskaja oblast')» utverzhden Sovetom po proektnomu upravleniju pri $\mathrm{Gu}-$ bernatore Rostovskoj oblasti [Passport regional project «Digital technologies (Rostov region)» approved by the Council on project management in the Governor of the Rostov region] (Protokol ot 20.04.2020 g. №6).

9. Rasporjazhenie Pravitel'stva RF ot 28.07.2017 g. №1632-r «Ob utverzhdenii programmy "Cifrovaja jekonomika Rossijskoj Federacii"» [The order of the Government of the Russian Federation dated 28.07.2017, №1632-R «On approval of the program "Digital economy of the Russian Federation"»].

10. Rejting RBK Rostov: top-10 promyshlennyh kompanij Dona za 2018 god ot 
21.08.2020 [Rating of RBC Rostov: top-10 industrial companies of the Don for 2018 from 21.08.2020] [Jelektronnyj resurs]. — URL: https://rostov.rbc.ru/rostov/21/08/2019/5d5d26ef9 a79471a78471a11/ (Date accessed: 29.09.2020).

11. «Rostsel'mash» i DGTU zajmetsja cifrovizaciej agropromyshlennogo kompleksa ot 14.07.2020 [«Rostselmash» and DSTU will be engaged in digitalization of the agro-industrial complex from 14.07.2020] [Jelektronnyj resurs]. — URL: https://rostselmash.com/company/press/news/show/1186/ (Date accessed: 29.09.2020).

12. TMK vnedrjaet cifrovye tehnologii v sistemu operativnogo upravlenija proizvodstvom ot 05.08.2020 [TMK implements digital technologies in the system of operational production management from 05.08.2020] [Jelektronnyj resurs]. — URL: https://www.comnews.ru/digital-economy/content/208464/2020-08-05/2020w32/tmk-vnedryaet-cifrovye-tekhnologii-sistemu-operativnogo-upravleniya-proizvodstvom (Date accessed: 29.09.2020).

13. Fedotova G. V. Problemy cifrovizacii promyshlennogo sektora [Problems of digitalization of the industrial sector] // Nacional'nye interesy: prioritety i bezopasnost' [National interests: priorities and security]. — 2019. №2. - Pp. 273-283.

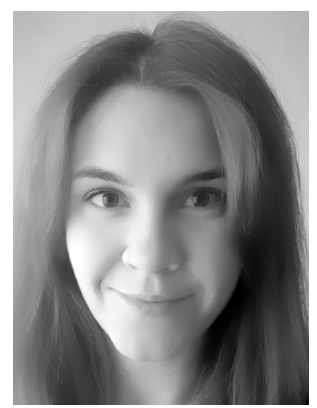

Калинина Антонина Михайловна - магистрант направления 270406 «Организация и управление наукоемкими производствами» кафедры «Производственный и инновационный менеджмент» Южно-Российского государственного политехнического университета (НПИ) имени М. И. Платова.

Kalinina Antonina Mikhailovna - Master's student of the direction 270406 «Organization and management of high-tech industries» of the «Production and Innovation Management» Department, Platov South Russian State Polytechnic University (NPI).

346428, г. Новочеркасск, ул. Просвещения, 132 132 Prosveshcheniya st., 346428, Novocherkassk, Russia E-mail: pvo78@yandex.ru 


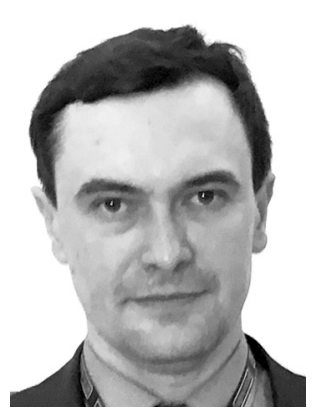

Куликов Михаил Михайлович - кандидат экономических наук, доцент кафедры «Производственный и инновационный менеджмент» Южно-Российского государственного политехнического университета (НПИ) имени М. И. Платова.

Kulikov Mikhail Mikhailovich - Candidate of Economic Sciences, Associate Professor of «Production and Innovation Management» Department, Platov South Russian State Polytechnic University (NPI).

346500, г. Шахты, ул. Пролетарская, 176, кв. 2

176 Proletarskaya st., app. 2, 346500, Shakhty, Russia

E-mail: kulikovmichael@mail.ru 